\title{
Atypical antipsychotics as add-on treatment in late-life depression
}

This article was published in the following Dove Press journal:

Clinical Interventions in Aging

9 September 2016

Number of times this article has been viewed

\author{
Sibel Cakir ${ }^{\prime}$ \\ Zeynep Senkal ${ }^{2}$ \\ 'Department of Psychiatry, Mood \\ Disorders, Geriatric Psychiatry Unit, \\ Istanbul Medical School, Istanbul \\ University, ${ }^{2}$ Department of Psychiatry, \\ Marmara University, Istanbul, Turkey
}

Correspondence: Sibel Cakir Department of Psychiatry, Mood Disorders, Geriatric Psychiatry Unit, Istanbul Medical School, Istanbul University, Millet Cad 34390 Çapa/Fatih, Istanbul, Turkey

Fax +90 2I2 635 I204

Email drsibelcakir@yahoo.com
Background: Second-generation antipsychotics (SGAs) have been used in the augmentation of treatment-resistant depression. However, little is known about their effectiveness, tolerability, and adverse events in the treatment of late-life depression, which were the aim of this study. Methods: The retrospective data of patients aged $>65$ years who had a major depressive episode with inadequate response to antidepressant treatment and had adjuvant SGA treatment were analyzed. The outcome measures were the number of the patients who continued to use SGAs in the fourth and twelfth weeks, adverse events, and changes in symptoms of depression.

Results: Thirty-five patients were screened: 21 (60\%) had quetiapine, twelve (34.28\%) had aripiprazole, and two $(5.71 \%)$ had olanzapine adjuvant treatment. The mean age was $72.17 \pm 5.02$ years, and $65.7 \%$ of the patients were women. The mean daily dose was $85.71 \pm 47.80 \mathrm{mg}$ for quetiapine, $3.33 \pm 1.23 \mathrm{mg}$ for aripiprazole, and $3.75 \pm 1.76 \mathrm{mg}$ for olanzapine. The Geriatric Depression Scale scores of all patients were significantly decreased in the fourth week and were significant in the aripiprazole group $(P=0.02)$. Of the 35 patients, $23(65.7 \%)$ patients discontinued the study within 12 weeks. The frequency of adverse events was similar in all SGAs, and the most common were sedation, dizziness, constipation, and orthostatic hypotension with quetiapine, and akathisia and headache because of aripiprazole.

Conclusion: This study indicates that dropout ratio of patients with SGAs is high, and a subgroup of patients with late-life depression may benefit from SGAs. Effectiveness is significant in aripiprazole, and adverse events of SGAs were not serious but common in elderly patients.

Keywords: treatment resistance, aripiprazole, quetiapine, olanzapine, elderly

\section{Introduction}

Major depression is common in the elderly and results in increased mortality, disability, and suicide. ${ }^{1,2}$ It is estimated that in 2020 late-life depression (LLD) will be a significant public health problem and the second greatest cause of overall disability following heart disease. ${ }^{3,4}$ However, the response to initial first-line pharmacologic treatment of LLD is $<50 \% .^{5-7}$ Currently, treatment resistance is defined by the following parameters: failure to achieve remission with one antidepressant trial and failure with two trials of adequate dose and duration. ${ }^{8}$ Randomized controlled trials in LLD exhibit treatment resistance rates up to $77 \%$ when selective serotonin reuptake inhibitors (SSRIs) are applied, which varies between 55\% and $81 \%$ with serotonin/ norepinephrine reuptake inhibitors. ${ }^{8}$ Despite the fact that there is growing evidence from the Sequenced Treatment Alternatives to Relieve Depression study regarding the treatment-resistant depression (TRD) in the general population, evidence-based guidelines for the elderly are lacking. ${ }^{3,9}$ Impaired executive functions in LLD and magnetic resonance imaging white matter hyperintensities are more frequently known 
to accompany LLD as a vascular depression hypothesis. ${ }^{10,11}$ Both the factors are associated with treatment resistance and prone to antidepressant adverse effects. ${ }^{7}$ Medical comorbidities, increased susceptibility to adverse effects, consequences of polypharmacy, and changes in metabolism should be considered in the treatment of the LLD. ${ }^{3}$

Antipsychotics as an alternative augmentation approach in the treatment of depression have received noticeable attention in recent years. ${ }^{1,12-16}$ Three second-generation antipsychotics (SGAs), aripiprazole, quetiapine, and olanzapine-fluoxetine, have been approved by the United States Food and Drug Administration as an add-on treatment for adult TRD. ${ }^{17}$ Yet, there is a remarkable lack of consistent evidence for the use of SGAs for LLD regarding efficacy and safety. The aim of this study was to investigate the effectiveness and tolerability/safety of SGAs as add-on treatment for LLD.

\section{Methods}

We conducted a retrospective study involving patients aged $\geq 65$ years who were diagnosed with major depression and LLD and followed up regularly in the Geriatric Psychiatry Outpatient Clinic of Istanbul University, Istanbul Medical Faculty, between January 1, 2008, and January 1, 2016. Patients who were receiving adjuvant SGAs for their antidepressant treatment were recruited. The admission and follow-up procedures of the clinic were coordinated with a semi-structured interview and some standardized measures, which are outlined below. When patients were admitted to the clinic, physical, and neurological examinations, blood tests for thyroid functions, other blood/urine tests, and neuroimaging examinations were required to be taken according to provisional diagnosis. Geriatric Depression Scale (GDS) was designed as a self-administered, easy-to-use instrument for screening elder population. ${ }^{18}$ The format of the "yes/no" questions is more suitable to detect LLD. Vegetative symptoms such as sleep, appetite, and libido changes are affected by aging, and they might be false-positive signs for depression. These items may not be as reliable as the core symptoms of depression in diagnosing LLD, and they are not included in GDS. GDS was routinely applied at each visit, baseline, fourth week, and every month or every 3 months according to the remission in patients with LLD. Basic cognitive examinations such as Mini-Mental State Examination (MMSE) were also required every 3 months. ${ }^{19}$

The data of the patients were screened, and the data of patients who met the inclusion criteria were analyzed. All the patients provided written informed consent for analyzing their data, and ethical approval was obtained from the Institutional Review Board of Istanbul Medical Faculty.

\section{Patients}

The inclusion criteria were as follows:

1) Aged $\geq 65$ years; 2) Diagnosed as having major depressive disorders according to the Diagnostic and Statistical Manual of Mental Disorders, 4th Edition criteria; 3) Having first depressive episode when aged $>65$ years (ie, LLD); 4) Prescribed an SGA as adjuvant treatment to antidepressant treatment; 5) Absence of bipolar disorders, dementia, and other neurologic disorders.

\section{Outcome measures}

1) Percentage of patients who stayed on the SGAs throughout the study (4-12 weeks); 2) Change in GDS with scores at baseline, 4 weeks, and 12 weeks; 3) Percentage of patients who developed serious and nonserious adverse events (a semi-structured questionnaire was asked routinely upon initiation of a new medication).

Patients who achieved remission could not be investigated because the response and remission criteria with GDS were not well studied in the literature. Adverse events were collected in two ways: spontaneous reports of patients and questions of semi-structured follow-up interview. The interview consisted of questions/items related to mood, cognitive functions, functionality, activities of daily living, medications, and adverse event subdivisions. Adverse event items were summarized using a modified version of the UKU Side Effect Rating Scale. ${ }^{20}$

\section{Statistics}

All statistical analyses were performed and descriptive values, frequencies, percentages for categorical variables, mean, median, and standard deviation values for continuous variables were determined using Statistical Package for Software Analysis Version 16.0 (SPSS Inc., Chicago, IL, USA). The normally distributed continuous variables such as GDS and MMSE were compared using Student's $t$-test at baseline. GDS change was assessed using the Wilcoxon test between baseline and 4 weeks. Chi-square $\left(\chi^{2}\right)$ test and Fisher's exact test were used for the comparison of categorical variables such as adverse events between the SGA types. The level of statistical significance was determined at $P \leq 0.05$. Adverse events frequency was analyzed using the chi-square test. 


\section{Results}

We analyzed 264 patients; of these, 113 patients had augmentation or combination treatment, the remaining 151 patients had antidepressant monotherapy treatment. Of the 113 patients, 35 patients met the inclusion criteria for augmentation treatment of SGAs: $21(60 \%)$ patients received quetiapine, twelve (34.3\%) had aripiprazole, and two had olanzapine (5.7\%) adjuvant treatment. The data of all patients were analyzed descriptively; the mean age of the 35 patients was $72.2 \pm 5$ years (range, 65-82 years), and $23(65.7 \%)$ were women. The mean number of depressive episodes was $1.9 \pm 1.1$ (range, $1-5$ ). The mean dose of quetiapine was $85.7 \pm 47.8 \mathrm{mg}$ (range, 50-200 mg), aripiprazole was $3.3 \pm 1.2 \mathrm{mg}$ (range, $2.5-5 \mathrm{mg}$ ), and olanzapine was $3.7 \pm 1.8 \mathrm{mg}$ (range, $2.5-5 \mathrm{mg}$ ). The mean GDS scores of 35 patients were $20.2 \pm 2.9$ (range,

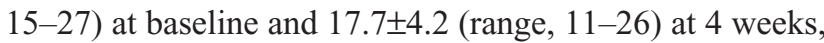
and the change was statistically different $(P<0.001$ and $z$ score $=3.9)$. Of the 35 patients, $23(65.7 \%)$ discontinued the SGA within the first 12 weeks.

The data of the patients with quetiapine and aripiprazole were compared to investigate the possible differences. Two patients with olanzapine were excluded because comparison would not be possible with so few cases. Table 1 shows descriptions, demographics, and clinical characteristics of the patients who received quetiapine and aripiprazole. The mean age, sex, and education levels were similar across the two treatment groups. Medical comorbidities were also similar, except diabetes. Aripiprazole was prescribed more in patients with depression who had comorbid diabetes. The antidepressant medication included selective serotonin reuptake inhibitors, serotonin/norepinephrine reuptake inhibitors, and a combination of both groups; the distribution of antidepressant type was not different across the quetiapine and aripiprazole groups. The dropout ratios were $42.8 \%$ vs $33.3 \%(P=0.43)$ in the quetiapine versus aripiprazole groups at 4 weeks and $23.8 \%$ vs $41.7 \%(P=0.24)$ between the fourth and twelfth weeks. The frequency of patients who completed the study was low, and there was no difference between the groups $(33.3 \%$ vs $25 \%, P=0.46)$. The mean GDS scores were not different across the treatment groups at baseline (Table 1). GDS change between baseline and 4 weeks in each treatment group was assessed using the Wilcoxon test. There was a significant decrease in the aripiprazole group, but not in the quetiapine group ( $P=0.02$ vs $P=0.16$; Table 2 ). Only seven $(33.3 \%)$ patients in the quetiapine group and three $(25 \%)$ in the aripiprazole group completed the study; the numbers of patients were low for the comparison of GDS
Table I Characteristics of study patients

\begin{tabular}{|c|c|c|c|}
\hline & $\begin{array}{l}\text { Quetiapine } \\
(n=2 I)\end{array}$ & $\begin{array}{l}\text { Aripiprazole } \\
(n=12)\end{array}$ & $P$-value \\
\hline Age, mean $(S D)$ & 72.1 (5.3) & $71.0(4.6)$ & $0.53 * *$ \\
\hline $\begin{array}{l}\text { Mean number of depressive } \\
\text { episodes (SD) }\end{array}$ & $1.9(1.2)$ & $\mathrm{I} .83(\mathrm{I} . \mathrm{I})$ & $0.77 * *$ \\
\hline Female (\%) & II (52.4) & $8(66.6)$ & $0.48^{*}$ \\
\hline Mean education, years (SD) & $6.3(4.3)$ & $6.83(4.5)$ & $0.73 * *$ \\
\hline Psychotic features (\%) & $5(23.8)$ & $4(33.3)$ & $0.42 *$ \\
\hline Having medical illness (\%) & $16(76.2)$ & $10(83.3)$ & 0.49 \\
\hline Hypertension & II (52.4) & $5(4 \mid .6)$ & 0.47 \\
\hline Diabetes & $5(23.8)$ & $7(58.3)$ & 0.05 \\
\hline Orthopedic & $4(19.0)$ & $3(25)$ & $0.50 *$ \\
\hline Other & $5(23.8)$ & $4(33.3)$ & $0.42 *$ \\
\hline Mean dosage, mg (SD) & $85.71(47.8)$ & $3.3(1.2)$ & \\
\hline $\begin{array}{l}\text { Mean number of medications } \\
\text { for medical illness }(S D)\end{array}$ & $2.38(1.4)$ & $2.16(1.2)$ & $0.64 * *$ \\
\hline $\begin{array}{l}\text { Dropout ratio at the } \\
\text { fourth week (\%) }\end{array}$ & $9(42.8)$ & $4(33.3)$ & $0.43 *$ \\
\hline $\begin{array}{l}\text { Dropout ratio between the } \\
\text { fifth and twelfth weeks (\%) }\end{array}$ & $5(23.8)$ & $5(4 \mid .7)$ & 0.24 \\
\hline $\begin{array}{l}\text { Number of patients } \\
\text { completed } 12 \text { weeks (\%) }\end{array}$ & $7(33.3)$ & $3(25)$ & $0.46^{*}$ \\
\hline Mean GDS, baseline (SD) & $20.3(3.0)$ & I9.9| (2.8) & $0.4 I^{* *}$ \\
\hline Mean GDS, 4 weeks (SD) & $\begin{array}{l}18.7(4.8) \\
n=12\end{array}$ & $\begin{array}{l}17.12(2.5) \\
n=8\end{array}$ & \\
\hline Mean GDS, 12 weeks (SD) & $\begin{array}{l}19.00(4.9) \\
n=7\end{array}$ & $\begin{array}{l}14.7(3.0) \\
n=3\end{array}$ & \\
\hline Mean MMSE, baseline (SD) & $26.9(1.1)$ & $27.1(I .1)$ & $0.65 * *$ \\
\hline Mean MMSE, 12 weeks (SD) & $27.6(I . I)$ & $27.7(1.2)$ & $0.75 * *$ \\
\hline $\begin{array}{l}\text { Number of patients having } \\
\text { any adverse event (\%) } \\
\text { Type of antidepressants } \\
\text { combined with AAP }\end{array}$ & $13(61.9)$ & $5(4 \mid .6)$ & 0.22 \\
\hline SSRIs (\%) & $8(38.1)$ & $3(25)$ & $0.35 *$ \\
\hline SNRI (\%) & $6(28.6)$ & $4(33.3)$ & $0.53 *$ \\
\hline $\begin{array}{l}\text { Combination SSRI and } \\
\text { SNRI (\%) }\end{array}$ & $7(33.3)$ & $5(4 \mid .7)$ & 0.45 \\
\hline
\end{tabular}

Notes: *Fisher's exact test, **Student's t-test.

Abbreviations: AAP, atypical antipsychotic; GDS, Geriatric Depression Scale; MMSE, Mini-Mental State Examination; SD, standard deviation; SSRI, selective serotonin reuptake inhibitor; SNRI, serotonin/norepinephrine reuptake inhibitor.

scores at 12 weeks. MMSE scores were also recorded; there was no difference across the groups at baseline and at 12 weeks $(P=0.65$ and $P=0.75$, respectively). The one patient who received olanzapine completed the study.

Table 2 GDS score difference between baseline and the fourth week

\begin{tabular}{|c|c|c|c|c|c|c|}
\hline & \multicolumn{3}{|l|}{ Quetiapine } & \multicolumn{3}{|l|}{ Aripiprazole } \\
\hline & $\begin{array}{l}\text { Median } \\
\text { (min-max) }\end{array}$ & z & $P$-value* & $\begin{array}{l}\text { Median } \\
\text { (min-max) }\end{array}$ & $z$ & $P$-value* \\
\hline $\begin{array}{l}\text { Baseline } \\
\text { GDS }\end{array}$ & $20(16-26)$ & 1.38 & 0.16 & $20(15-24)$ & 2.2 & 0.02 \\
\hline $\begin{array}{l}\text { Fourth } \\
\text { week GDS }\end{array}$ & 19.5 (II-27) & & & $17(|3-2|)$ & & \\
\hline
\end{tabular}

Note: *Wilcoxon test.

Abbreviations: GDS, Geriatric Depression Scale; max, maximum; min, minimum. 
Table 3 Adverse events in the add-on treatment of SGA

\begin{tabular}{lll}
\hline & Quetiapine & Aripiprazole \\
\hline & $2 \mathrm{I}$ & 12 \\
Number of patients experiencing AEs (\%) & $\mathrm{I} 4(66.7)$ & $7(58.3)$ \\
Sedation & $7(33.3)$ & $\mathrm{I}(8.3)$ \\
Dizziness & $6(28.6)$ & $2(16.7)$ \\
Increased appetite & $4(19.0)$ & $\mathrm{I}(8.3)$ \\
Weight gain & $4(19.0)$ & $2(16.7)$ \\
Gastrointestinal events (eg, constipation & $5(23.8)$ & $3(25)$ \\
and nausea) & & \\
EPS & - & $\mathrm{I}(8.3)$ \\
Akathisia & $\mathrm{I}(4.76)$ & $5(41.7)$ \\
Orthostatic hypotension & $5(23.8)$ & $\mathrm{I}(8.3)$ \\
Headache & $\mathrm{I}(4.8)$ & $3(25)$ \\
\hline
\end{tabular}

Note: Data presented as $\mathrm{n}(\%)$.

Abbreviations: AE, adverse event; EPS, Extrapyramidal Symptoms; SGA, secondgeneration antipsychotics.

There were no life-threatening adverse events in either group (Table 3). However, the frequency of adverse events was not low ( $66.7 \%$ for quetiapine vs $58.3 \%$ for aripiprazole), and the groups were not statistically different regarding the adverse event frequency $(P=0.45)$. The two patients with olanzapine had weight gain, sedation, and constipation.

\section{Discussion}

Despite some limitations, compared with randomized trials, this was a real-world study that provided valuable observations from a geriatric mental health clinic. The main findings of this study were that there was a high percentage of dropout with SGAs; a subgroup of patients had benefits with SGAs, which was significant with aripiprazole for decreasing symptoms of depression; and there was a high percentage of nonserious adverse events with SGAs. The high and remarkable dropout rate was observed within the first 3 months of this study. Patients who used quetiapine were more likely to discontinue medication in the first 4 weeks, whereas aripiprazole users discontinued in the following weeks. This finding indicates that the tolerance of quetiapine in the first few weeks was insufficient and that slow titration could be beneficial. The ratio of patients who completed the study was remarkably low (1:3).

Compared with the two previous studies, the higher frequency of dropouts and adverse events of this study may be attributed to the real-world data, which differ from controlled interventions. ${ }^{1,14}$ More frequent visits of controlled trials may allow for better drug adherence. The dropout ratio of the elderly patients with SGAs has not been well documented in the literature, yet dropout ratio seems to be an important indicator of efficacy. Our findings regarding adverse events, dropout rate, and efficacy were concordant in this study. This finding highlights the difficulty of continuing ineffective medications with adverse events.
We observed that a subgroup of patients with SGA adjuvant treatment had benefits in reducing the symptoms of depression. We observed a significant improvement in depressive symptoms overall in patients starting from the fourth week. The patients who were on aripiprazole treatment tended to have a greater decrease in the symptoms of depression in the fourth week, even in a relatively small sample. There was a decrease in the mean GDS score in patients receiving quetiapine, but it was not statistically significant at the fourth week. The adjuvant treatment of SGAs was found efficacious in TRD in adult patients. ${ }^{21}$ However, little is known about the effectiveness of SGAs in LLD. Only one randomized, double-blind, placebo-controlled study and two open-label studies showed that aripiprazole was effective and had an acceptable rate of adverse events in the treatment of LLD, as we found in this study. ${ }^{1,1314}$ Two open-label studies have shown favorable results for quetiapine augmentation. ${ }^{15,22}$ Further studies are required to understand the efficacy and safety of quetiapine, and comparing it with other SGAs in the treatment of LLD.

Quetiapine was the most prescribed SGA as an adjuvant treatment in this study group, aripiprazole followed quetiapine, and olanzapine was the least prescribed SGA. Even with relatively low doses, we observed large numbers of adverse events with SGAs in more than half of the patients. The frequency of adverse events was comparable in quetiapine and aripiprazole groups; nonetheless, various adverse events were observed across the two groups. The adverse events of sedation, dizziness, and gastrointestinal adverse events, increased appetite, and weight gain were frequent with quetiapine, whereas akathisia and headache were more common in the aripiprazole group. No patients had somnolence associated with quetiapine as reported in some previous studies. ${ }^{23,24}$ This may be because quetiapine is titrated slowly with low doses in our geriatric psychiatry clinic. Akathisia was more frequent among aripiprazole users than among quetiapine users in this study, and also more than in the literature. ${ }^{1}$ Parkinsonism was not observed among the patients who were on aripiprazole as reported earlier, owing to the lower dose of aripiprazole in this study. ${ }^{1}$

We acknowledge that the duration of this study was short at 3 months, and longer use of SGAs may result in more or serious adverse events, which previously served as warnings regarding mortality in geriatric patients. ${ }^{25,26}$ The small number of study patients might also be the reason for the absence of life-threatening adverse events. Among the SGAs, metabolic syndrome (ie, diabetes, weight gain, and hyperlipidemia) is more common with olanzapine and clozapine and less reported with quetiapine and especially 
with aripiprazole. ${ }^{27}$ In our study sample, olanzapine was not prescribed frequently, and aripiprazole was more preferred in patients with diabetes. The reported adverse events data with SGAs were provided from patients with dementia. ${ }^{28}$ Patients with dementia and depression, even those of similar age, may experience adverse events differently. In our study, it was considered that patients with LLD may experience more frequent adverse events with SGAs and tolerate these drugs less than patients with dementia. However, the self-reports of the patients with dementia may not reflect the reality of adverse events because they report less and are less aware.

\section{Limitations}

The retrospective design of the study may cause inadequate data collection. Metabolic markers such as blood level of lipids, glucose, and other blood tests were not collected in the third month. Accordingly, the patients' psychological, neurological, and physical adverse events and tolerability were investigated using subjective measures (self-reports). The sample size of the study was relatively small, which may have affected the results. Adverse events were not collected with standardized screening tools; adverse events were investigated with spontaneous self-reports by patients and questions in a semi-structured interview, which was routinely used in follow-up visits.

The duration of the study was limited to 3 months, and the long-term adverse effects of SGAs were not studied. The efficacy of olanzapine as an adjuvant treatment in TRD was also reported; however, the number of patients who had olanzapine treatment was too small in our study sample to give some opinion regarding efficacy, tolerability, and adverse events. Thus, this retrospective observation study is limited to two SGAs. Lastly, GDS is routinely used in the geriatric population; however, this instrument is not preferred for the screening of the pharmacologic treatment outcomes and thus the use of GDS may have some drawbacks. There have been a few studies published on the evaluation of GDS for measuring change or improvement in depression. ${ }^{29,30}$ Also, the definition of remission with GDS is not clear; thus, we evaluated the change in GDS instead of remission. Therefore, the results regarding the effectiveness of SGA should be interpreted with caution.

\section{Conclusion}

In conclusion, the tolerability of SGAs as an adjuvant treatment was low, and the dropout rate was high in the treatment of LLD. SGAs, especially aripiprazole, may have efficacy as an adjuvant treatment of LLD. These results should be interpreted with US Food and Drug Administration warnings of increased risks of cerebrovascular events with SGAs, when using them in a low-dosage regimen and short term. ${ }^{31,32}$ This favorable efficacy and adverse events profile requires further controlled, comparison studies to clarify which SGA is better for geriatric patients.

\section{Disclosure}

The authors report no conflicts of interest in this work.

\section{References}

1. Lenze EJ, Mulsant BH, Blumberger DM, et al. Efficacy, safety, and tolerability of augmentation pharmacotherapy with aripiprazole for treatment-resistant depression in late life: a randomised, double-blind, placebo-controlled trial. Lancet. 2015;386(10011):2404-2412.

2. Whiteford HA, Degenhardt L, Rehm J, et al. Global burden of disease attributable to mental and substance use disorders: findings from the Global Burden of Disease Study 2010. Lancet. 2013;382(9904):1575-1586.

3. Cooper C, Katona C, Lyketsos K, et al. A systematic review of treatments for refractory depression in older people. Am J Psychiatry. 2011; 168(7):681-688.

4. Harman JS, Mulsant BH, Kelleher KJ, Schulberg HC, Kupfer DJ, Reynolds CF III. Narrowing the gap in treatment of depression. Int $J$ Psychiatry Med. 2001;31(3):239-253.

5. Smagula SF, Butters MA, Anderson SJ, et al. Antidepressant response trajectories and associated clinical prognostic factors among older adults. JAMA Psychiatry. 2015;72(10):1021-1028.

6. Mulsant BH, Blumberger DM, Ismail Z, Rabheru K, Rapoport MJ. A systematic approach to pharmacotherapy for geriatric major depression. Clin Geriatr Med. 2014;30(3):517-534.

7. Maust DT, Oslin DW, Thase ME. Going beyond antidepressant monotherapy for incomplete response in nonpsychotic late-life depression: a critical review. Am J Geriatr Psychiatry. 2013;21(10):973-986.

8. Lenze EJ, Sheffrin M, Driscoll HC, et al. Incomplete response in latelife depression: getting to remission. Dialogues Clin Neurosci. 2008; 10(4):419-430.

9. Rush AJ. Star-D: lessons learned and future implications. Depress Anxiety. 2011;28(7):521-524.

10. Alexopoulos GS, Meyers BS, Young RC, Campbell S, Silbersweig D, Charlson M. 'Vascular depression' hypothesis. Arch Gen Psychiatry. 1997; 54(10):915-922.

11. Krishnan KR, McDonald WM. Arteriosclerotic depression. Med Hypotheses. 1995;44(2):111-115.

12. Bauer M, Dell'osso L, Kasper S, et al. Extended-release quetiapine fumarate (quetiapine XR) monotherapy and quetiapine XR or lithium as add-on to antidepressants in patients with treatment-resistant major depressive disorder. J Affect Disord. 2013;151(1):209-219.

13. Rutherford B, Sneed J, Miyazaki M, et al. An open trial of aripiprazole augmentation for SSRI non-remitters with late-life depression augmentation. Int J Geriatr Psychiatry. 2007;22(10):986-991.

14. Sheffrin M, Driscoll HC, Lenze EJ, et al. Pilot study of augmentation with aripiprazole for incomplete response in late-life depression: getting to remission. J Clin Psychiatry. 2009;70(2):208-213.

15. Carta MG, Zairo F, Mellino G, Hardoy MC. Add-on quetiapine in the treatment of major depressive disorder in elderly patients with cerebrovascular damage. Clin Pract Epidemiol Ment Health. 2007;26(3):28.

16. Tadger S, Paleacu D, Barak Y. Quetiapine augmentation of antidepressant treatment in elderly patients suffering from depressive symptoms: a retrospective chart review. Arch Gerontol Geriatr. 2011;53(1): 104-105.

17. Zhou X, Keitner GI, Qin B, et al. Atypical antipsychotic augmentation for treatment-resistant depression: a systematic review and network meta-analysis. Int J Neuropsychopharmacol. 2015;18(11):pyv060.

18. Yesavage JA, Brink TL, Rose TL, et al. Development and validation of a geriatric depression screening scale: a preliminary report. J Psychiat Res. 1983;17(1):37-49. 
19. Folstein MF, Folstein SE, McHugh PR. "Mini-mental state". A practical method for grading the cognitive state of patients for the clinician. J Psychiatr Res. 1975;12(3):189-198.

20. Lingjaerde O, Ahlfors UG, Bech P, Dencker SJ, Elgen K. The UKU side effect rating scale. A new comprehensive rating scale for psychotropic drugs and a cross-sectional study of side effects in neuroleptic-treated patients. Acta Psychiatr Scand Suppl. 1987;334:1-100.

21. Papakostas GI, Shelton RC, Smith J, Fava M. Augmentation of antidepressants with atypical antipsychotic medications for treatment-resistant major depressive disorder: a meta-analysis. J Clin Psychiatry. 2007; 68(6):826-831.

22. Tadger S, Paleacu D, Barak Y. Quetiapine augmentation of antidepressant treatment in elderly patients suffering from depressive symptoms: a retrospective chart review. Arch Gerontol Geriatr. 2011;53(1): 104-105.

23. Madhusoodanan S, Brenner R, Alcantra A. Clinical experience with quetiapine in elderly patients with psychotic disorders. $J$ Geriatr Psychiatry Neurol. 2000;13(1):28-32.

24. Tariot PN, Salzman C, Yeung PP, Pultz J, Rak IW. Long-term use of quetiapine in elderly patients with psychotic disorders. Clin Ther. 2000; 22(9):1068-1084.

25. Schneider LS, Dagerman KS, Insel P. Risk of death with atypical antipsychotic drug treatment for dementia: meta-analysis of randomized placebo controlled trials. JAMA. 2005;294(15):1934-1943.
26. Gill SS, Bronskill SE, Normand SL, et al. Antipsychotic drug use and mortality in older adults with dementia. Ann Intern Med. 2007;146(11): 775-786.

27. Newcomer JW. Metabolic considerations in the use of antipsychotic medications: a review of recent evidence. J Clin Psychiatry. 2007; 68(Suppl 1):20-27.

28. Zheng L, Mack WJ, Dagerman KS, et al. Metabolic changes associated with second-generation antipsychotic use in Alzheimer's disease patients: the CATIE-AD study. Am J Psychiatry. 2009;166(5):583-590.

29. Sheikh JI, Yesavage JA. Geriatric Depression Scale (GDS): recent evidence and development of a shorter version. In: Brink TL, editor. Clinical Gerontology: A Guide to Assessment and Intervention. New York, NY: The Haworth Press; 1986:165-173.

30. Scogin F. The concurrent validity of the Geriatric Depression Scale with depressed older adults. Clin Gerontologist. 1987;7(1):23-31.

31. Jeste DV, Blazer D, Casey D, et al. ACNP white paper: update on use of antipsychotic drugs in elderly persons with dementia. Neuropsychopharmacology. 2007;33(5):957-970

32. FDA. Public Health Advisory. Deaths with antipsychotics in elderly patients with behavioral disturbances; 2010. Available from: www.fda. gov/drugs/drugsafety/postmarketdrugsafetyinformationforpatientsandproviders/ucm053171. Accessed May 1, 2016.
Clinical Interventions in Aging

\section{Publish your work in this journal}

Clinical Interventions in Aging is an international, peer-reviewed journal focusing on evidence-based reports on the value or lack thereof of treatments intended to prevent or delay the onset of maladaptive correlates of aging in human beings. This journal is indexed on PubMed Central, MedLine,

\section{Dovepress}

CAS, Scopus and the Elsevier Bibliographic databases. The manuscript management system is completely online and includes a very quick and fair peer-review system, which is all easy to use. Visit http://www.dovepress. com/testimonials.php to read real quotes from published authors. 